\title{
A FIDELIDADE E SUAS CONTROVÉRSIAS
}

\author{
Geocinara de Faria Avila \\ Universidade de Campinas \\ lugeoavila@uol.com.br
}

\begin{abstract}
Resumo: Este trabalho visa, através do paralelismo entre a visão logocêntrica e a desconstrutivista, buscar em suas bases teóricas possíveis respostas para uma das indagações pertinentes à fidelidade na tradução: "O que é ser fiel"? Veremos que ao tratar essa questão evidenciam-se controvérsias entre as diversidades e abordagens teóricas aqui apresentadas.
\end{abstract}

Palavras-Chave: tradução, fidelidade, logocentrismo, desconstrução.

\begin{abstract}
This paper aims through a parallelism between the logocentric and the deconstructivistic views, to search in both theories an answer to one of the questions regarding fidelity in translation: "What is it to be faithful"? We will note controversy during the presentation of these views.
\end{abstract}

Keywords: translation, fidelity, logocentrism, desconstruction.

\section{Introdução}

Há temas que parecem ter os seus momentos de ápice, mas em se tratando de "fidelidade" as publicações têm revelado que este, além de polêmico há séculos, vem sendo tratado com relevância em diversas áreas, sendo a da tradução o foco de interesse neste trabalho.

Assim é que iniciamos com a pergunta "O que é ser fiel?", visando fazer um paralelismo entre a visão logocêntrica e a desconstrutivista, buscando em suas bases teóricas possíveis res- 
postas. Como ponto de partida, podemos considerar a definição extraída do dicionário Luft de que "fiel" é "cumprir o que prometeu'. Sendo assim, o que o tradutor considerado infiel, prometeu e não cumpriu?

Segundo Arrojo (1986: 42), "Se pensamos a tradução como um processo de recriação ou transformação, como podemos falar em fidelidade? Como poderemos avaliar a qualidade de uma tradução?".

\section{Logocentrismo e desconstrução}

Começando pela abordagem estruturalista, temos na visão logocêntrica a marca evidente das dicotomias entre sujeito/objeto, teoria/prática e forma/conteúdo. O papel do tradutor neste caso é o de transpositor de significados, já que a leitura neste contexto é considerada única. A tradução é vista como transporte, sem contaminação na passagem de um texto de uma língua para outra, pois caso contrário haveria perda e traição.

Há uma preocupação por parte daqueles que compartilham esta idéia de buscar incessantemente uma sistematização teórica, acreditando ser esta a chave na resolução dos problemas existentes no campo da tradução, neste caso, o da fidelidade. Porém, Ottoni (2005c: 49) enfatiza que "a tradução não é domesticável em si, ela resiste a qualquer tentativa de sistematização em qualquer postura teórica ou histórica".

Partindo dessa citação de Ottoni, uma analogia neste momento talvez pudesse propiciar uma reflexão quanto à busca de sistematização teórica na tradução. Consideremos a possibilidade de fazer parte do processo de um tratamento doloroso para uma específica enfermidade uma teoria sistematizada cujo resultado, no entanto, não fosse atingido na prática, já que cada enfermo poderia responder de maneira diferente ao determinado tratamento. Assim talvez seja o processo da tradução: a tentativa de sistematizá-la e teorizála para resolver os problemas na prática pode não atingir as expec- 
tativas dos envolvidos, por exemplo, autor, editor, revisor e tradutor, já que os últimos respondem de maneiras diferentes às tensões sofridas durante o processo tradutório, produzindo diferentes textos como produtores de significados.

Nesse contexto é que se insere o pensamento desconstrutivista visando promover a reflexão e problematização das abordagens estruturalistas.

Retomando a questão da fidelidade: segundo Ottoni (2005c: 52) "na dimensão desconstrutivista as questões da fidelidade e da correlação privilegiada entre as línguas não são mais pertinentes para tratar do transbordamento e do jogo da multiplicidade de línguas envolvidas na tradução", já que:

A tradução é um acontecimento que deflagra a língua e as várias línguas presentes num mesmo sistema lingüístico. Esta postura de Derrida (cf. 1982, p.134) ${ }^{6}$ frente à tradução vai numa direção diferente da postura estrutural e da pósestruturalista ao chamar a atenção para o jogo de significação entre as línguas que ocorre em qualquer tradução desconstrução (ibidem).

É nesse jogo de significação que o tradutor participa produzindo significados e outras "impurezas" na língua de chegada, ocorrendo assim o transbordamento de significados de uma língua para outra, e é nessa dimensão que Ottoni (2005) enfatiza que a questão da fidelidade já não é pertinente, pois se há impurezas, há contaminação, sendo as línguas neste caso, encaradas como pólos complementares, elas não se distinguem. Assim,

Tradicionalmente a tradução se apóia numa teoria ou numa história, a partir de uma concepção da linguagem que faz uma distinção estanque entre duas línguas, na tentativa de manter intactos esses pólos, em oposição, e não levando em conta sua complementaridade (Ottoni, 2005a: 73). 
Na tentativa de validar a tese de que os tradutores são produtores de significados, seguem abaixo alguns trechos traduzidos da obra de Jonathan Swift As Viagens de Gulliver, os quais foram selecionados e comentados por Gabriel Perissé na Revista Língua Portuguesa de nov-2006, pp. 58-61.

"[...] challenging him to wrestle, and such repartees as are usual in the mouths of court pages" (apud Perissé, 2006: 60).

\section{Cruz Teixeira}

"uma vez mais o tradutor preferiu fazer vista grossa e passar por cima do trecho" (Perissé, 2006: 60).

Octavio Mendes Cajado

"[...] desafiando-o a lutar e dando-lhe as outras respostas que de ordinário se encontram na boca dos pajens da corte" (apud Perissé, 2006: 60).

Therezinha Monteiro Deutsch

"[...] e o desafiei para uma luta, num tipo de reação comum entre os pajens da corte" (apud idem).

\section{Ildásio Tavares}

"[...] desafiando-o a lutar e coisas tais, que são comuns nas bocas de pajens da corte" (apud idem).

"(for I verily think he was not full thirty foot high)" (apud idem).

\section{Cruz Teixeira}

"a omissão é intencional. Para Cruz Teixeira, é permitido ao tradutor ignorar palavras e trechos do original" (Perissé, 2006: 60).

Octavio Mendes Cajado

"[...] pois creio, efetivamente, que não alcançava trinta pés de altura" (apud Perissé, 2006: 60). 
Therezinha Monteiro Deutsch

"[...] acredito que ele não tinha mais do que nove metros de altura" (apud idem).

Ildásio Tavares

"[...] o tradutor não considerou relevante essa informação para a compreensão da idéia fundamental do parágrafo". (Perissé, 2006: 60) "and he seldom failed of a smart Word or two upon my littleness" (apud Perissé, 2006: 61).

Cruz Teixeira

"[...] e zombava incessantemente da minha pequena estatura" (apud idem).

Octavio Mendes Cajado

"[...] e raro deixava de fazer um ou dois chistes a respeito da minha pequenez' (apud idem).

Therezinha Monteiro Deutsch

"[...] ele até mesmo chegou a fazer uma ou duas pilhérias sobre a minha pequenez" (apud idem).

Ildásio Tavares

"[...] raro deixava de soltar um gracejo sobre minha pequenez" (apud idem).

Os exemplos apresentados dos trechos traduzidos vêm validar a tese de que os tradutores são produtores de significado.

\section{Possíveis Respostas as Indagações}

Acerca das questões principais abordadas no início deste trabalho, "O que é ser fiel?" e "O que o tradutor considerado infiel, 
prometeu e não cumpriu?" Derrida, na tradução de Ottoni "Fidelidade a Mais de Um" (2005b: 195) esclarece:

Apesar de tudo, parece que a tradução deve se esforçar para ser o mais fiel possível, não pela preocupação de exatidão calculável, mas porque ela nos lembra a lei do outro texto, a sua assinatura, esse outro acontecimento que já teve lugar antes de nós, e ao qual nós devemos responder como herdeiros.

A citação acima parece esclarecer sobre o comprometimento do tradutor em seu exercício, quando indica que a tradução nos lembra a lei do outro texto, a sua assinatura, ou seja, o tradutor não precisa prometer, ele já assumiu e se comprometeu no momento da tradução, do acontecimento.

\section{Considerações Finais}

Diante das abordagens e citações mencionadas neste trabalho, que pretende contribuir para o contínuo crescimento de produção de conhecimentos, vimos que a questão da fidelidade é um tema complexo sobre o qual deve-se refletir ao adotar certa posição que julgamos ser ideal para aplicação nos estudos da tradução ou na sua prática profissional. Ottoni (2005c: 48) lembra que:

À medida que as novas posturas perante a tradução se
fortalecem, é fundamental nos debruçarmos sobre os
pressupostos que sustentam essas reflexões. Descartada a
abordagem estrutural e formal de base lingüística, não é fácil
traçar uma linha divisória e simplesmente passarmos a
considerar tudo o que se faz atualmente a partir das concepções
pós-estruturalistas da linguagem, em oposição ao que se fazia
anteriormente, como possíveis soluções às questões que a
tradução traz. (...) Se, por um lado, uma lingüística estrutural 
e formal não dá conta de sistematizar e teorizar a tradução no interior de uma ciência, por outro, na abordagem pósestruturalista a tradução passa a ser considerada como uma questão ideológica e filosófica.

Nesse contexto se evidencia a importância de considerar para os estudos da tradução, ambas as abordagens estruturalistas e pósestruturalistas como elementos que poderão dar suporte ao tradutor diante das várias questões que possivelmente se confrontarão em suas práticas profissionais.

De qualquer forma, como diz Benjamin (2001), a teoria de tradução está preocupada com outras questões e não somente com a reprodução de sentido, além do quê, como visto, o conceito de fidelidade é contraditório e parece não contar com uma solução apropriada.

\section{Bibliografia}

ARROJO, Rosemary. Oficina de Tradução: a teoria na prática. São Paulo: Ática, 1986.

BENJAMIN, Walter. "A Tarefa/Renúncia do Tradutor". Trad. de Susana K. Lages. In Clássicos da Teoria da Tradução. Florianópolis: NUT/UFSC. 2001.

LUFT, Celso Pedro. Minidicionário Luft. São Paulo: Ática, 2003.

OTTONI, Paulo. "A Tradução é Desde Sempre Resistência: Reflexões Sobre Teoria e História da Tradução". In: Tradução Manifesta - double bind \& acontecimento. Campinas: UNICAMP e EDUSP, 2005a. 
. "Fidelidade a Mais de Um - Merecer Herdar Onde a Genealogia Falta, de Jacques Derrida". In Tradução Manifesta: Double Bind \& Acontecimento. Campinas: UNICAMP, 2005b.

. "Tradução Recíproca e Double Bind: Transbordamento e Multiplicidade de Línguas". In: Tradução Manifesta - double bind \& acontecimento. Campinas: UNICAMP e EDUSP, 2005c.

PERISSÉ, Gabriel. As Viagens Vernaculares de Gulliver. Língua Portuguesa, São Paulo, SP, ano II, n. 13, nov. 2006, pp. 58-61. 